\section{- OPEN ACCESS}

\title{
Work-unit organisational changes and subsequent prescriptions for psychotropic medication: a longitudinal study among public healthcare employees
}

\author{
Johan Høy Jensen, ${ }^{1,2}$ Jens Peter Bonde, ${ }^{1}$ Esben Meulengracht Flachs, ${ }^{1}$ Janne Skakon, ${ }^{3}$ \\ Naja Hulvej Rod, ${ }^{4}$ Ichiro Kawachi ${ }^{2}$
}

\begin{abstract}
- Additional material is published online only. To view please visit the journal online (http://dx.doi.org/10.1136/ oemed-2018-105442).
\end{abstract}

'Department of Occupational and Environmental Medicine, Copenhagen University Copenhagen, Denmark 'Department of Social and Behavioral Sciences, Harvard T.H. Chan School of Public Health, Boston, Massachusetts, USA ${ }^{3}$ Department of Psychology, University of Copenhagen, Copenhagen, Denmark ${ }^{4}$ Section of Epidemiology, Department of Public Health, University of Copenhagen, Copenhagen, Denmark

Correspondence to Johan Høy Jensen, Department of Occupational and Environmental Medicine, Copenhagen University Hospital, Bispebjerg Hospital Copenhagen 2400, Denmark;

Received 20 August 2018 Revised 19 November 2018 Accepted 27 November 2018 Published Online First 7 January 2019 Hospital, Bispebjerg Hospital, johan.hoey.jensen@regionh.dk

\section{ABSTRACT \\ Objectives We examined exposure to different types of organisational changes at work as risk factors for subsequent prescription for psychotropic medication among employees.}

Methods The study population included 15038 public healthcare employees nested within 1284 work units in the Capital Region of Denmark. Multilevel mixed-effects parametric survival models were developed to examine time to prescription for psychotropic medications (anxiolytics/hypnotics/sedatives/antidepressants) during the 12-month interval following exposure to organisational changes relative to no change from January to December 2013. Data on work-unit level organisational changes (including mergers, split-ups, relocation, change in management, employee layoffs and budget cuts) were collected from work-unit managers (59\% response).

Results Any organisational change versus no change was associated with a higher risk of psychotropic prescription (HR: 1.14, 95\% Cl: 1.02 to 1.26), especially change in management (HR: $1.23,95 \% \mathrm{Cl}: 1.07$ to 1.41). Splitting the 12-month follow-up period into two halves yielded particularly high rates of psychotropic prescription in the latter half of the follow-up, for example, any change (HR: $1.25,95 \% \mathrm{Cl}: 1.11$ to 1.41$)$, change in management (HR: $1.42,95 \% \mathrm{Cl}: 1.22$ to 1.65$)$, mergers (HR: 1.26, 95\% Cl: 1.06 to 1.50), employee lay-off (HR: $1.23,95 \% \mathrm{Cl}: 1.03$ to 1.46) and budget cuts (HR: $1.13,95 \% \mathrm{Cl}: 1.00$ to 1.41). The associations did not vary by sex.

Conclusions Organisational changes in the workplace, especially change in management, may be associated with increased risk of psychotropic prescription among employees regardless of sex.

\section{INTRODUCTION}

(C) Author(s) (or their employer(s)) 2019. Re-use permitted under CC BY-NC. No commercial re-use. See rights and permissions. Published by BMJ.

To cite: Jensen $\mathrm{JH}$

Bonde JP, Flachs EM,

et al. Occup Environ Med

2019;76:143-150.
Depressive and anxiety disorders are estimated to be the third and ninth leading causes, respectively, of disability globally. ${ }^{1}$ Most people spend many of their waking hours in an occupational setting, and workplace conditions thus play a key role for employee well-being. Organisational changes in the workplace (eg, downsizing or mergers) are often implemented as a strategy to maximise competitiveness in a globalised economy. ${ }^{23}$

\section{Key messages}

What is already known about this subject?

- Different types of organisational changes at work may have different negative effects on stress-related prescriptions for psychotropic medication among male and female employees.

What are the new findings?

- Organisational changes in the workplace were associated with higher risk of prescription for psychotropic medication in the following year relative to no change in the workplace.

- This association was particularly strong for exposure to change in management and prescriptions for antidepressants, but results did not vary by sex or previous history of psychotropic medication prescription.

- Splitting the 12-month follow-up period into two halves yielded the strongest effects during the latter period after different types of change, suggesting a latency period before excess use of psychotropic medication.

- Factors at the work-unit level accounted for $6 \%$ of the total variance in prescriptions for psychotropic medication, indicating that this level is an important contributor to use of psychotropic medication among employees.

How might this impact on policy or clinical practice in the foreseeable future?

- Decision-makers and policy-makers should consider that different types of organisational change in the workplace may pose risks for employee mental health.

Organisational changes at work seem to have adverse impacts on employee health and wellbeing. ${ }^{4-8}$ Although evidence supports an association between individual reporting of higher psychosocial stress and excess risk of depression, ${ }^{9}$ anxiety ${ }^{1011}$ and disturbed sleep, ${ }^{12}$ longitudinal associations between organisational changes and stress-related clinical psychiatric disorders remain unclear. ${ }^{13}$

Some studies found excess self-reported psychiatric symptoms following changes including downsizing and mergers, ${ }^{14-17}$ but inconsistent 
findings have also been reported. ${ }^{13} 18$ Negative appraisals of mergers has been linked to 1.60 -fold higher risk of a psychiatric event ${ }^{19}$; however, this association may likely be inflated due to underlying negative affectivity influencing both exposure and outcome. ${ }^{20}$ Another study found 1.03-1.16-fold higher relative risk of total sickness absence for $\geq 2$ simultaneous change types, mergers, change in management and budget cuts, ${ }^{5}$ suggesting that employees react differently to different change types. ${ }^{21}$

Studies on organisational changes and prescriptions for psychotropic medication ${ }^{22-25}$ mainly focused on major company downsizing ( $\geq 18 \%$ staff reduction) to find associations with higher relative risk of psychotropic prescriptions. ${ }^{22-24}$ Associations stratified by sex showed similar patterns of prescriptions in Swedish studies, ${ }^{23} 24$ with higher relative risk for prescriptions among male employees (RR: 1.49, 95\% CI: 1.10 to 2.02) compared with female employees (RR: 1.12, 95\% CI: 1.00 to 1.27$)$ in the Finnish study. ${ }^{22}$ This sex difference could be due to greater job demands and lower social support among men. ${ }^{26}$

A Danish study on company changes targeting specific dimensions showed that changes regarding cooperation/coordination and, especially, those targeting multiple dimensions were associated with higher prescription rates, ${ }^{25}$ suggesting a cumulative effect of multiple changes. These prescription effects were stronger in the first year than the 2-year period after changes. No associations were found for changes targeting effectiveness, adaptation/turbulence or skill/knowledge enhancement. ${ }^{25}$

Indeed, these prior studies of organisational changes and psychotropic prescriptions may be subject to exposure misclassification (ie, employees not experiencing the changes personally) since change data were defined at the company level. Also, none of the studies used multilevel modelling to account for potential clustering of psychotropic prescriptions within the organisational structure of workplaces ${ }^{27}$ which may elevate risk of type-I error. $^{28}$

The literature highlights organisational changes as a heterogenous short-term risk factor for clinical mental health problems among employees since specific and multiple simultaneous changes seem to be associated with higher risk of psychotropic prescriptions in the years closer to the change event. Sex differences in this association remain unclear although some evidence suggest more adverse effects among men. To better understand and potentially mitigate development of negative employee effects of organisational changes, there is a need to examine the short-term associations between objective measures of specific change types and prescriptions for psychotropic medication accounting for multilevel clustering.

This study contributes to the literature by using multilevel modelling to investigate the putative associations between specific types of work-unit organisational changes and excess rates of prescription for psychotropic medication among employees during the subsequent year. We hypothesised excess prescription rates to vary immediately after specific types of organisational change. Stronger cumulative prescription effects were expected after multiple simultaneous changes. Also, we hypothesised more adverse change effects on psychotropic prescriptions among males relative to females. We examined these potential sex differences in terms of both additive (ie, absolute risk) and multiplicative interaction between changes and males (ie, relative risk) since these two types of interaction may be observed independently. ${ }^{29}$

\section{METHODS}

\section{Study design, data sources and population}

We examined the prospective association between exposure to work-unit organisational changes during the observation period through 2013 and prescription of psychotropic medication during the ensuing 12-month follow-up period among employees (between 1 January 2014 (baseline) and 31 December 2014). All participants were part of the ongoing Well-being in Hospital Employees cohort study. ${ }^{30}$ The source population included all 37720 healthcare employees nested in 2696 work units from 14 institutions comprising the capital region of Denmark. A work unit was defined as a group of employees referring to same immediate manager. Data on organisational changes were gathered April-June 2016 via a survey distributed to all managers of these work units (59\% response). Complete data on occupational/sociodemographic information at baseline and prescription of psychotropic medication from 2011 to 2014 were extracted via linkage to company and national registers, respectively.

Eligible employees $(n=25897)$ nested in 2318 work units at baseline were identified based on the following inclusion criteria: working in work units with $\geq 3$ employees, $\geq 1$ year of seniority in the same work unit, $\geq 18.5$ weekly working hours throughout 2013, not working multiple positions, not working in Denmark or aged $\geq 18$. We allowed for $\geq 1$ year of seniority in a work unit changing name during the observation period of organisational changes by including employees if $\geq 3$ co-workers and $\geq 30 \%$ of the work-unit staff remained in the work unit after the name change. These criteria were applied in keeping with a previous approach. ${ }^{51}$ We excluded 10859 eligible employees with missing data on organisational changes. The study population comprised 15038 employees nested in 1284 work units (figure 1).

There were no significant differences between the source population, eligible employees and the study population regarding sex composition $(\mathrm{p}=0.15)$ or prescriptions for psychotropic medication $(p=0.62)$ as indicated by $\chi^{2}$ tests. Nurses were slightly overrepresented in the groups of eligible and studied employees $(43 \%)$ relative to the source population (41\%), whereas medical doctors/dentists were somewhat under-represented among eligible (11\%) and studied employees (10\%) compared with the source population $(14 \%)(\mathrm{p}<0.001)$.

\section{Work-unit level organisational changes}

We collected data on exposure to different types of organisational changes at the work-unit level by administering a questionnaire via working email to all work-unit managers from April to June 2016. The managers provided information on occurrence of the following specific types of organisational changes in their work unit for each semester during 2013, viz, mergers, split-ups, relocation, change in management, employee lay-off or budget cuts. Responses for 2013 were collapsed because we did not collect information on when the changes were announced or initiated within the company. We created seven change-indicator variables at the work-unit level: six variables for each of the types of organisational changes and one variable for 'any changes' (yes/no change). None of the individual types of changes were completely overlapping as co-occurrence rates were $\leq 56 \%$ (online supplementary material 1).

\section{Employee-level prescriptions for psychotropic medication}

For outcome purposes, we used information from 1 January to 31 December 2014 on the date of psychotropic prescriptions 


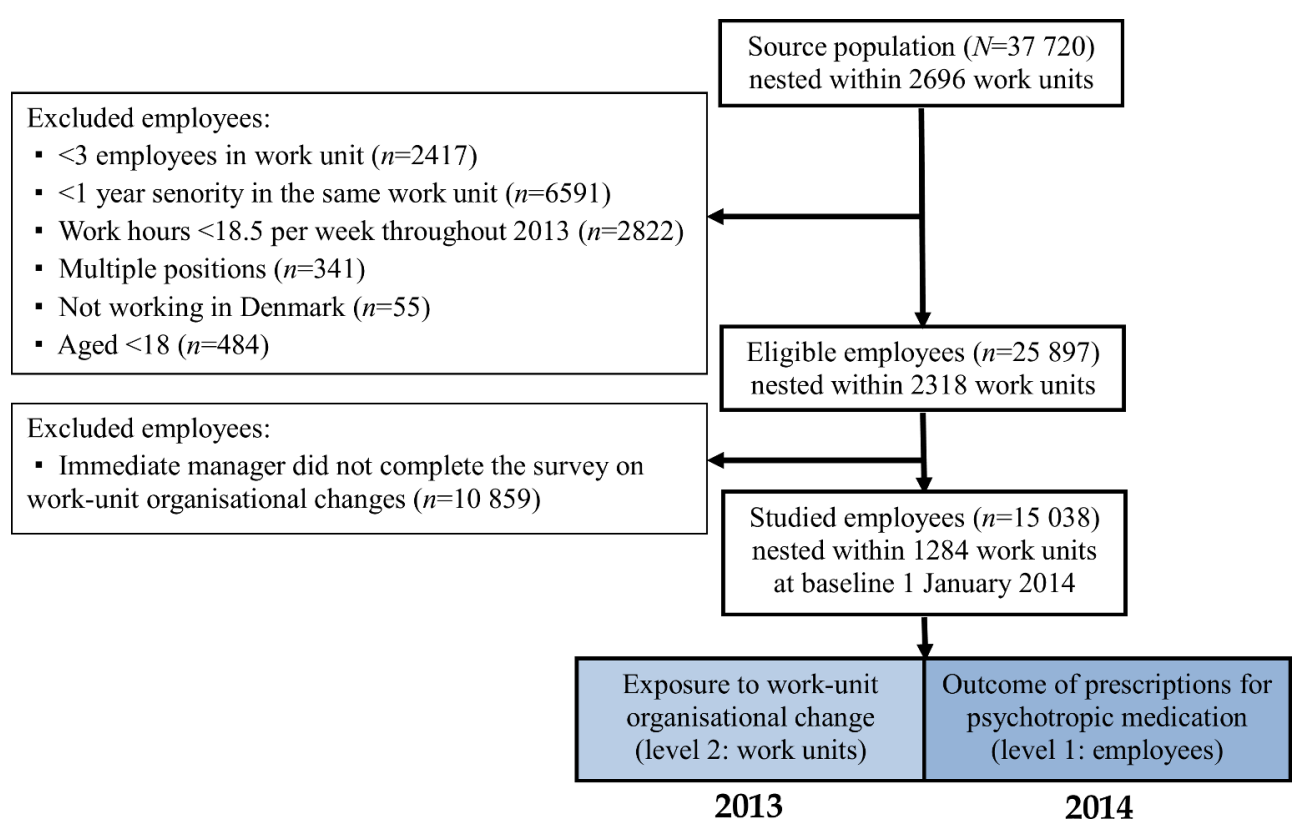

Figure 1 Flow of the study population and study design. Employees could fulfil multiple exclusion criteria.

including anxiolytics (WHO Anatomical Therapeutic Chemical (ATC) code: N05B), hypnotics/sedatives (N05C) and antidepressants (N06A). These data were used regardless of the prescribed daily dose or period for intended use. Although follow-up data on psychotropic prescriptions in 2015 were available, we did not use these because we presumed that psychotropic prescriptions in 2015 would be highly impacted by organisational changes in 2014, on which we had no information.

\section{Employee and work-unit level covariates}

We used the following employee-level variables as a priori covariates: age, sex, occupational group, manager, personal gross income, fixed weekly working hours, contractual employment, years of seniority and days of sickness absence in 2012. We did not consider prior psychotropic prescriptions to be a potential confounder because we presumed no causal impact of employee-level psychotropic prescriptions on subsequent workunit organisational changes.

As work-unit level a priori covariates, we used the number of employees within the work unit and selected types of organisational changes confounding other types of changes (online supplementary material 2). For example, we regarded work-unit mergers and split-ups as confounders for the relation between change in management and psychotropic prescriptions. All covariates were categorical variables (table 1).

\section{Statistical analysis}

We estimated HR and 95\% CI using multilevel mixed-effects parametric survival models to study the association between organisational changes in 2013 and psychotropic prescriptions in 2014. Employees (level 1) were nested within work units (level 2). Analyses were unable to converge in threelevel models nesting work units within institutions. Employees were followed from 1 January 2014 to the first psychotropic prescription (event), death (censoring) or end of study by 31 December 2014, whichever came first. The relative impact of each change-indicator variable (adjusted for other changes as appropriately) were evaluated in separate models.

Parametric survival models follow a specified distribution from which residual variance at multiple levels is estimated. In a null model, residual variance at the work-unit level reflects the relative importance of any work-unit factors for psychotropic prescriptions among employees. We fitted a Weibull distribution to the survival models as we expected the hazard of psychotropic prescriptions to either increase or decrease during follow-up ${ }^{32}$ since the magnitude and exact date of the change announcements were unclear. We applied Acceleration Failure Time parametrisation for the Weibull models which allows for estimation of the intraclass correlation coefficient (ICC) for work units. ${ }^{33}$ We interpreted ICC $* 100$ as the proportion of any work-unit factors-observed and unobserved-explaining the total variance in psychotropic prescriptions among employees.

A four-step sequential modelling strategy with incremental adjustment for covariates was used to assess confounding and variation in prescriptions explained by the work-unit level (online supplementary material 3).

We analysed the association between any changes and each subgroup of psychotropic medication (ie, anxiolytics, hypnotics/sedatives and antidepressants) first prescribed in 2014 to assess their relative importance. Sex differences in change effects on psychotropic prescriptions were evaluated in additive interaction analysis (ie, combined effect) by calculating the synergy index $(S)^{34}$ and $95 \% \mathrm{CI}^{35}$ as well as in multiplicative interaction analysis by including an interaction term between indicator variables of any change and male adjusted for the separate main effects of change and sex. We estimated additive interaction between any changes and females since we were unable to calculate $95 \%$ CI to $S$ for any changes and males (online supplementary material 4).

\section{Sensitivity analyses}

We reran the analysis for any changes and psychotropic prescriptions during 2014 additionally adjusting for potential confounding 
Table 1 The two-level data structure and distribution of variables for the study population and employees/work units exposed to any organisational changes

\begin{tabular}{|c|c|c|c|}
\hline & Categories & Study population, $\mathrm{n}$ (\% of $\mathrm{N}$ ) & Exposed to any changes, $\mathrm{n}(\%$ of $\mathrm{N})$ \\
\hline Level 1: employees, $\mathrm{N}$ & & $15038(100)$ & $8242(55)$ \\
\hline $\begin{array}{l}\text { Prescription for psychotropic medication } \\
\text { in } 2014\end{array}$ & & $1616(11)$ & $931(11)$ \\
\hline Days to first prescription, M (SD) & & $107(101)$ & $109(103)$ \\
\hline \multirow[t]{4}{*}{ Age group } & $19-40 *$ & $3821(25)$ & $2093(25)$ \\
\hline & $40-48$ & $3780(25)$ & $2056(25)$ \\
\hline & $48-56$ & $3728(25)$ & $2027(25)$ \\
\hline & $56-75$ & $3709(25)$ & $2066(25)$ \\
\hline \multirow[t]{2}{*}{ Sex } & Female* & $11507(77)$ & $6299(76)$ \\
\hline & Male & $3531(23)$ & $1943(24)$ \\
\hline \multirow[t]{6}{*}{ Occupational group } & Nurses* & $6534(43)$ & $3682(45)$ \\
\hline & Medical doctors/dentists & $1464(10)$ & $758(9)$ \\
\hline & Social/healthcare workers & $1966(13)$ & $1055(13)$ \\
\hline & Pedagogical workers & $401(3)$ & $217(3)$ \\
\hline & Service/technical workers & $1864(12)$ & $975(12)$ \\
\hline & Administration workers & $2809(19)$ & $1555(19)$ \\
\hline \multirow[t]{4}{*}{ Seniority, years } & $1-4^{*}$ & $3125(21)$ & $173(21)$ \\
\hline & $5-10$ & $3818(25)$ & $2076(25)$ \\
\hline & $11-20$ & $4097(27)$ & $2239(27)$ \\
\hline & $21 \leq$ & $3998(27)$ & $2197(27)$ \\
\hline \multirow[t]{2}{*}{ Manager } & No* & $14040(93)$ & $7591(92)$ \\
\hline & Yes & $998(7)$ & $651(8)$ \\
\hline \multirow[t]{3}{*}{ Weekly working hours } & $18.5-32^{*}$ & $2662(18)$ & $1511(18)$ \\
\hline & $32-37$ & $3643(24)$ & $2023(25)$ \\
\hline & $37 \leq$ & $8733(58)$ & $4708(57)$ \\
\hline \multirow[t]{2}{*}{ Contractual employment } & No* & $1066(7)$ & $487(6)$ \\
\hline & Yes & $13972(93)$ & $7755(94)$ \\
\hline \multirow[t]{4}{*}{ Personal gross income, DKK } & $\leq 345000^{*}$ & $4427(29)$ & $2458(30)$ \\
\hline & $345000-400000$ & $3862(26)$ & $2124(26)$ \\
\hline & $400000-480000$ & $3471(23)$ & $1852(22)$ \\
\hline & $\geq 480000$ & $3278(22)$ & $1808(22)$ \\
\hline \multirow[t]{5}{*}{ Sickness absence in 2012 , days } & No days* & $4132(27)$ & $2274(28)$ \\
\hline & $1-3$ & $3242(22)$ & $1760(21)$ \\
\hline & $4-6$ & $2292(15)$ & $1271(15)$ \\
\hline & $7-13$ & $2877(19)$ & $1517(18)$ \\
\hline & $\geq 14$ & $2495(17)$ & $1420(17)$ \\
\hline Level 2: work units, $\mathrm{N}$ & & $1284(100)$ & \\
\hline \multirow[t]{8}{*}{ Organisational changes } & No changes* & $642(50)$ & \\
\hline & Any changes & $642(50)$ & \\
\hline & Mergers & $195(15)$ & \\
\hline & Split-ups & $75(6)$ & \\
\hline & Relocation & $157(12)$ & \\
\hline & Change in management & $294(23)$ & \\
\hline & Employee lay-off & $245(19)$ & \\
\hline & Budget cuts & $191(15)$ & \\
\hline \multirow[t]{4}{*}{ Number of employees within work unit } & $3-12^{*}$ & $654(51)$ & $283(44)$ \\
\hline & $13-22$ & $306(24)$ & $164(26)$ \\
\hline & $23-32$ & 198 (15) & 116 (18) \\
\hline & 33-142 & $126(10)$ & 79 (12) \\
\hline
\end{tabular}

\footnotetext{
*Reference category.
DKK, Danish Krone; M, mean.
}

by prior psychotropic prescriptions between 2011 and 2012 (ie, preceding changes that occurred in 2013) to evaluate confounding by prior psychotropic prescriptions. To assess if the association between change in management and psychotropic prescriptions was driven by (eg, laid-off) managers, we reran this analysis excluding all managers $(n=14040)$ for comparison with the analysis on the total study population. Associations with prescriptions through 2014 were analysed according to any changes in each semester of 2013 to evaluate possible temporality in change exposure. Finally, we analysed exposure 
to 1,2 or $3 \leq$ types of simultaneous changes compared with no changes to explore the potential cumulative effect on psychotropic prescriptions.

We used a significance level of 0.05 throughout. All statistical analyses were conducted using STATA V.14.2 software.

\section{RESULTS}

Table 1 presents the hierarchical data structure and distribution of employee- and work-unit level variables for the study population $(\mathrm{n}=15038)$ and among employees/work units exposed to any organisational changes $(n=8242)$. The study population predominantly comprised female employees, nurses, employees with $\geq 37$ weekly working hours (ie, full-time employment). Employees with prior psychotropic prescriptions between 2011 and 2012 were similarly distributed in the study population $(14 \%, \mathrm{n}=2049)$ and among employees exposed to any changes $(14 \%, n=1173)$, indicating no confounding by prior psychotropic prescriptions. Among the study population, 1616 employees (11\%) were prescribed psychotropic medication in 2014. More antidepressants $(52 \%, \mathrm{n}=833)$ and hypnotics/ sedatives $(38 \%, \mathrm{n}=614)$ were prescribed than anxiolytics $(13 \%, n=202)$. During the follow-up in 2014, eight employees died, and four of these deaths occurred before a psychotropic prescriptions (censoring).

Table 2 shows that any organisational changes in 2013 was associated with an HR of 1.14 (95\% CI: 1.02 to 1.26 ) for psychotropic prescriptions in 2014 relative to no changes. Medical doctors/dentists and employees aged 56-75 had particularly high HRs of psychotropic prescriptions. As reflected by the ICC, the correlation of psychotropic prescriptions between work units explained $6 \%$ of the total variation in psychotropic prescriptions. This indicates that work units are an important contributor to prescriptions for psychotropic medication among employees. Adjustment for employee and work-unit level covariates led to slightly higher HR of psychotropic prescriptions after any changes. Additional adjustment for potential confounding by prior psychotropic prescriptions in this model attenuated the association (HR: $1.08,95 \% \mathrm{CI}: 0.97$ to 1.20 ).

Following any organisational changes, there was a higher rate ratio for prescription of antidepressants (HR: 1.21, 95\% CI: 1.05 to 1.40 ) and indications of a higher rate ratio for prescription of anxiolytics (HR: 1.25, 95\% CI: 0.93 to 1.69), but no association for prescription of hypnotics/sedatives (HR: 1.00, 95\% CI: 0.85 to 1.19 ).

We only found weak indications of an additive interaction between any changes and females (S: $1.36,95 \% \mathrm{CI}: 0.32$ to 5.84; supplementary material 5) and no multiplicative interactions $(p=0.69)$. This indicates no differential effects of organisational changes regarding sex.

In table 3, the fully adjusted model 4 shows that change in management in 2013 was associated with a HR of 1.23 (95\% CI: 1.07 to 1.41 ) for psychotropic prescriptions in 2014 relative to no changes. This excess HR of psychotropic prescriptions remained in a sample excluding all managers $(n=14040$; HR: 1.24, 95\% CI: 1.07 to 1.42 ), indicating that the effect was not attributable to managers laid off. There were indications of higher prescription rates after mergers, employee lay-off or budgets cuts, but these findings were not statistically significant. Indeed, employee lay-off and budget cuts were statistically significantly associated with a higher rate of psychotropic prescriptions in model 3 adjusted for age, sex and socio-occupational factors. However, these effects attenuated in model 4 when additionally adjusting for mergers, change in management and budget cuts as confounders on the association between employee lay-offs and psychotropic prescriptions.

Table 4 presents the rate ratios of psychotropic prescriptions splitting the 12-month follow-up period into two halves. In the former follow-up period, only change in management was associated with a higher rate of psychotropic prescriptions. In the second period, exposure to any changes, mergers, change in management, employee lay-off or budget cuts were statistically significantly associated with a 1.19-1.42 times higher rate of psychotropic prescriptions relative to no change. Any changes occurring in the former and latter semester of 2013 were similarly associated with excess rates of psychotropic prescriptions through 2014 (HR: 1.11, 95\% CI: 0.99 to 1.24 and HR: 1.16, 95\% CI: 1.04 to 1.29 , respectively), suggesting a comparable effect of the exposure on outcome over time. There were no meaningful differences between prescription rates following exposure to 1,2 or $3 \leq$ types of simultaneous changes relative to no change in either half follow-up period, indicating no cumulative effects by multiple changes (data not shown).

\section{DISCUSSION}

More than half of the studied employees were exposed to organisational changes. We found higher risk of prescriptions for psychotropic medication among employees in the year after they remained in the work unit during any organisational changes compared with no changes. This association was particularly strong following change in management and in relation to prescription of antidepressants. Splitting the follow-up period into two halves yielded a stronger association in the latter half of the 12-month follow-up compared with the former half, indicating a latency period before an increase in prescriptions. The observed association did not vary according to sex.

Our findings of a 1.09-fold and 1.25-fold higher rate ratio of psychotropic prescriptions in the former and the latter halves of the year after any changes, respectively, corroborate with prior findings from another Danish study of a 1.09-fold higher rate of psychotropic prescriptions which was strongest in the year immediately after the changes. ${ }^{25}$ In our study, this association was particularly strong for change in management which, to our knowledge, has not been reported before. Among both men and women, we found a roughly 1.15 -fold higher rate over the 12-month follow-up which is comparable with the Finnish 10-Town study estimate of a 1.12 times higher rate of psychotropic drug prescription after major downsizing among women. In that same study, the prescription rates were notably higher among male employees (1.49), ${ }^{22}$ whereas in our study the interaction analyses yielded no sex differences in line with other studies. ${ }^{23}{ }^{24}$ In fact, sex did not predict psychotropic prescriptions significantly in the present study. This could be due to limited statistical power since only $357(2 \%)$ male employees were prescribed psychotropic medications during follow-up. Also, we found no cumulative effects of exposure to multiple changes $(1,2$ or $3 \leq)$ which contradicts previous findings of comprehensive changes being particularly associated with excess risk of psychotropic prescriptions. ${ }^{25}$ This may be explained by excess employee turnover rates during a greater number simultaneous changes as indicated by a prior study. ${ }^{5}$

Adjusting the association between changes and psychotropic prescriptions during 2014 for prior psychotropic prescriptions between 2011 and 2012 attenuated the HR from 1.14 to 1.08 ; however, this reduction towards the null may be explained by the introduction of an index event bias ${ }^{36}$ as episodes of mental disorders are highly recurrent in a workplace context. ${ }^{37}$ Index 
Table 2 HR of prescription for psychotropic medication in $2014(n=1616)$ among the study population $(n=15038)$

\begin{tabular}{|c|c|c|c|c|c|}
\hline \multirow[b]{3}{*}{ Fixed part } & \multicolumn{5}{|c|}{ Prescription, follow-up 1 January to 31 December 2014} \\
\hline & \multirow[t]{2}{*}{ Model 1} & \multicolumn{2}{|c|}{ Model 2} & \multicolumn{2}{|c|}{ Model 3} \\
\hline & & $\mathrm{HR}$ & $95 \% \mathrm{Cl}$ & HR & $95 \% \mathrm{Cl}$ \\
\hline \multicolumn{6}{|l|}{ Work-unit level variables (level 2) } \\
\hline Any organisational changes* & & 1.13 & 1.02 to 1.26 & 1.14 & 1.02 to 1.26 \\
\hline \multicolumn{6}{|l|}{ Number of employees within work unit† } \\
\hline $13-22$ & & & & 1.00 & 0.86 to 1.15 \\
\hline $23-32$ & & & & 0.95 & 0.81 to 1.10 \\
\hline $33-142$ & & & & 0.82 & 0.70 to 0.96 \\
\hline \multicolumn{6}{|l|}{ Individual-level variables (level 1) } \\
\hline \multicolumn{6}{|l|}{ Age group $\ddagger$} \\
\hline $40-48$ & & & & 1.41 & 1.19 to 1.69 \\
\hline $48-56$ & & & & 1.68 & 1.40 to 2.00 \\
\hline $56-75$ & & & & 2.09 & 1.73 to 2.51 \\
\hline Male§ & & & & 0.88 & 0.77 to 1.02 \\
\hline \multicolumn{6}{|l|}{ Occupational group } \\
\hline Medical doctors/dentists & & & & 2.33 & 1.85 to 2.88 \\
\hline Social/healthcare workers & & & & 0.95 & 0.80 to 1.13 \\
\hline Pedagogical workers & & & & 0.89 & 0.63 to 1.25 \\
\hline Service/technical workers & & & & 0.94 & 0.77 to 1.16 \\
\hline Administrative workers & & & & 1.17 & 1.00 to 1.35 \\
\hline \multicolumn{6}{|l|}{ Seniority, years** } \\
\hline $5-10$ & & & & 1.10 & 0.94 to 1.28 \\
\hline $11-20$ & & & & 1.00 & 0.85 to 1.19 \\
\hline$\geq 21$ & & & & 0.99 & 0.82 to 1.19 \\
\hline Manager, yest† & & & & 0.97 & 0.79 to 1.21 \\
\hline \multicolumn{6}{|l|}{ Weekly working hours $\ddagger \ddagger$} \\
\hline $32-37$ & & & & 1.00 & 0.85 to 1.17 \\
\hline$\geq 37$ & & & & 0.77 & 0.68 to 0.88 \\
\hline Contractual employment, yes§§ & & & & 1.00 & 0.82 to 1.22 \\
\hline \multicolumn{6}{|l|}{ Personal gross income, DKK१ף } \\
\hline $345000-400000$ & & & & 0.90 & 0.79 to 1.04 \\
\hline $400001-480000$ & & & & 0.85 & 0.72 to 0.98 \\
\hline$\geq 480001$ & & & & 0.86 & 0.71 to 1.03 \\
\hline \multicolumn{6}{|l|}{ Sickness absence in 2012 , days ${ }^{* * *}$} \\
\hline $1-3$ & & & & 0.91 & 0.77 to 1.07 \\
\hline $4-6$ & & & & 1.20 & 1.01 to 1.42 \\
\hline $7-13$ & & & & 1.52 & 1.30 to 1.78 \\
\hline$\geq 14$ & & & & 2.33 & 2.01 to 2.70 \\
\hline \multicolumn{6}{|l|}{ Random part } \\
\hline ICC (p value), work-unit level (level 2) & $0.06(<0.01)$ & $0.05(<$ & & 0.02 & \\
\hline \multicolumn{6}{|c|}{ 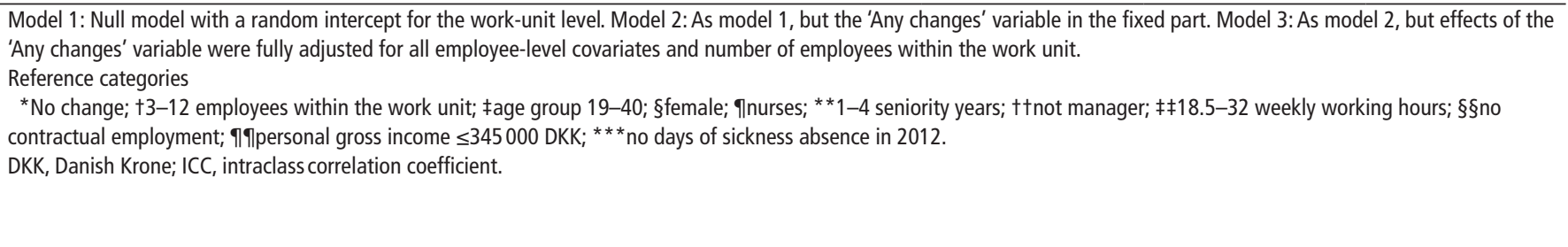 } \\
\hline \multicolumn{3}{|c|}{$\begin{array}{l}\text { event bias refers to the selection of participants based on index } \\
\text { events (prior prescriptions) for whom the putative risk factor } \\
\text { (changes) is associated with an observed lower probability of } \\
\text { new events (new prescriptions). Conditioning on prior psycho- } \\
\text { tropic prescriptions could actually 'protect' against new psycho- } \\
\text { tropic prescriptions as associated with organisational changes } \\
\text { because employees with mental illness would likely adapt their } \\
\text { working life according to their limited occupational capacity (eg, } \\
\text { not working full-time) which thus induces dependence between } \\
\text { otherwise independent confounder variables. In support to this } \\
\text { perspective, the descriptive statistics indicated no confounding }\end{array}$} & \multicolumn{3}{|c|}{$\begin{array}{l}\text { by prior psychotropic prescriptions, and the proportion of full- } \\
\text { time employees was in fact smaller among those with prior } \\
\text { psychotropic prescriptions }(53 \% \text { of } \mathrm{n}=2049) \text { than employees } \\
\text { without prior prescriptions }(59 \% \text { of } \mathrm{n}=12989) \text {. } \\
\text { It has previously been highlighted that adverse effects of } \\
\text { organisational changes at the workplace are primarily driven } \\
\text { by changes in job insecurity among employees. }{ }^{38} \text { This is in line } \\
\text { with findings of excess psychotropic prescription rates after } \\
\text { change in management or employee lay-off as such changes may } \\
\text { elevate uncertainty about future employment and new down- } \\
\text { sizing waves in the work unit. In addition, mergers were also }\end{array}$} \\
\hline
\end{tabular}


Table 3 HR of prescription of psychotropic medication in $2014(n=1616)$ according to each type of organisational changes in 2013 among the study population $(\mathrm{n}=15038)$

\begin{tabular}{|c|c|c|c|c|c|}
\hline & \multicolumn{5}{|c|}{ Prescription, follow-up 1 January to 31 December 2014} \\
\hline & \multirow[b]{2}{*}{$\mathrm{N}$ (\% prescriptions) } & \multicolumn{2}{|c|}{ Model 3} & \multicolumn{2}{|c|}{ Model 4} \\
\hline & & HR & $95 \% \mathrm{Cl}$ & HR & $95 \% \mathrm{Cl}$ \\
\hline Mergers & $2560(11.4)$ & 1.11 & 0.95 to 1.28 & $1.14^{*}$ & 0.97 to 1.34 \\
\hline Split-ups & $956(10.2)$ & 0.98 & 0.79 to 1.23 & $0.98 t$ & 0.78 to 1.23 \\
\hline Relocation & $1872(10.3)$ & 1.00 & 0.85 to 1.19 & $1.02 \ddagger$ & 0.84 to 1.24 \\
\hline Budget cuts & 2401 (11.6) & 1.15 & 1.00 to 1.34 & 1.129 & 0.95 to 1.31 \\
\hline
\end{tabular}

Results for covariates omitted as no noteworthy changes in estimates were observed relative to table 2.

Model 3: Each type of change indicator adjusted for all employee-level covariates and number of work-unit employee and in the fixed part and a random intercept for the workunit level. Model 4: As model 3, but each type of organisational changes additionally adjusted for other changes as potential confounders on the association with psychotropic prescriptions:

*Split-ups and Budget cuts; tbudget cuts; łmergers and Split-ups; §mergers, change in management and budget cuts; १९change in management.

associated with an excess rate of psychotropic prescriptions in the latter half of the 12-month follow-up period which could be hypothetically explained by subsequent reduction in redundant staff following mergers. We had, however, no data on changes during follow-up to test this. Adverse effects of organisational changes are also previously found to be mediated by changes in job strain. ${ }^{39}$ Hence, long-term changes in job strain may explain why the excess rate ratios of psychotropic prescriptions were observed to be stronger in the latter period of follow-up than the earlier period immediately following organisational changes. Managers have a key role in organising work, and a change in management may follow increased demands in work procedures (eg, excess work documentation) inducing further psychosocial repercussions among employees. In addition, demands of workunit productivity may not be adjusted to the staff composition after employee lay-offs which could lead to workload intensification among the remaining employees.

\section{Strengths and limitations}

The associations found in the present study may be underestimated because we were unable to adjust for organisational changes occurring during the 12-month follow-up on psychotropic prescriptions. Neither did we assess the effects on psychotropic prescriptions during or before the observation of organisational changes in 2013. It is, however, reasonable to assume that the majority of employees prescribed psychotropic medication in 2013 would extend their medical treatment into the follow-up period in 2014. Indeed, if an employee exited the work unit during 2013 (eg, due to common mental disorder), the participant would not be included in the study population. Data on changes in 2013 obtained from managers 3 years later may be influenced by recall bias; however, since the managers most likely executed the changes, this bias is considered minor. Finally, using composite change measures for 2013 limits conclusions on the duration of the latency period.

This study benefited from assessing the relative impact of various and frequently occurring types of organisational changes. These changes were measured at the work-unit level among employees who remained in the work unit during the observation of the changes. This approach ensured that the employees personally experienced the changes. Assessing various types of changes also allowed us to create a purer reference group not

Table 4 HR of prescription for psychotropic medication in the former period from January to June 2014 or in the latter period from July to December 2014 according to organisational changes in 2013 among the study population $(n=15038)$

\begin{tabular}{|c|c|c|c|c|c|c|c|}
\hline & \multirow{2}{*}{$\mathrm{N}$} & \multicolumn{3}{|c|}{$\begin{array}{l}\text { Prescription, follow-up } \\
1 \text { January to } 30 \text { June } 2014\end{array}$} & \multicolumn{3}{|c|}{$\begin{array}{l}\text { Prescription, follow-up } \\
1 \text { July to } 31 \text { December } 2014\end{array}$} \\
\hline & & $\begin{array}{l}\text { Prescriptions } \\
(n=1257), \% \text { of } N\end{array}$ & \multicolumn{2}{|c|}{ Fully adjusted model } & $\begin{array}{l}\text { Prescriptions } \\
(n=1268), \% \text { of } N\end{array}$ & \multicolumn{2}{|c|}{ Fully adjusted model } \\
\hline No changes & 6796 & 8.0 & 1.00 & & 7.5 & 1.00 & \\
\hline Any changes & 8242 & 8.6 & 1.09 & 0.97 to 1.22 & 9.3 & 1.25 & 1.11 to 1.41 \\
\hline Relocation & 1872 & 7.8 & $1.02 \ddagger$ & 0.82 to 1.28 & 8.6 & $1.16 \ddagger$ & 0.93 to 1.44 \\
\hline $\begin{array}{l}\text { Change in } \\
\text { management }\end{array}$ & 3781 & 9.2 & $1.20 \ddagger$ & 1.03 to 1.41 & 10.3 & $1.42 \ddagger$ & 1.22 to 1.65 \\
\hline Employee lay-off & 3204 & 9.0 & $1.16 \S$ & 0.97 to 1.39 & 9.6 & $1.23 \S$ & 1.03 to 1.46 \\
\hline Budget cuts & 2401 & 8.5 & $1.04 \uparrow$ & 0.87 to 1.24 & 9.5 & 1.199 & 1.00 to 1.41 \\
\hline
\end{tabular}

Results for covariates omitted as no noteworthy change in estimates were observed relative to table 2.

Fully adjusted model: 'Any changes' adjusted for all employee-level covariates and number of work-unit employee and in the fixed part and a random intercept for the work-unit level (model 3). Each type of organisational changes additionally adjusted for other changes as potential confounders on the association with psychotropic prescriptions:

*Split-ups and budget cuts; łbudget cuts; ‡mergers and split-ups; §mergers, change in management and budget cuts; ๆchange in management (model 4). 
exposed to any of these changes as opposed to previous studies focusing on a single type of change. In addition, the nesting of employees within work units enabled us to adjust for clustering within work units. It was also a strength of the study that we used independent data sources hampering bias due to common variance regarding the exposure and outcome variables. Finally, data on psychotropic prescriptions were extracted from highly reliable national registers adding to the validity of the findings.

More research and practitioner attention should be devoted to the temporality in adverse effects of specific change types since mental health effects may develop over an extended period following the change event. The present study has highlighted change in management as a particular risk factor for employee mental health, and elucidating the underlying psychosocial mechanisms on this longitudinal association is an objective for future studies.

Acknowledgements JHJ thanks University of Copenhagen, Julie Von Müllens Fond, Else \& Mogens Wedell-Wedellsborgs Fond, and the Graduate School of Public Health (at University of Copenhagen) for their financial contribution to his stay as a visiting researcher in Department of Social and Behavioral Sciences at Harvard T.H. Chan School of Public Health during this study.

Contributors JHJ had full access to all data provided in the present study, and $\mathrm{JHJ}$ takes responsibility for the integrity and the accuracy of the data analyses. All authors were responsible for the current study design. JHJ wrote the initial draft of the manuscript. All authors contributed to the present study and approved the final draft of the manuscript.

Funding This work was funded by the Danish Working Environment Research Fund (13-2015-03).

Competing interests None declared.

Patient consent for publication Not required.

Provenance and peer review Not commissioned; externally peer reviewed.

Open access This is an open access article distributed in accordance with the Creative Commons Attribution Non Commercial (CC BY-NC 4.0) license, which permits others to distribute, remix, adapt, build upon this work non-commercially, and license their derivative works on different terms, provided the original work is properly cited, appropriate credit is given, any changes made indicated, and the use is non-commercial. See: http://creativecommons.org/licenses/by-nc/4.0/.

\section{REFERENCES}

1 Vos T, Allen C, Arora M, et al. Global, regional, and national incidence, prevalence, and years lived with disability for 310 diseases and injuries, 1990-2015: a systematic analysis for the Global Burden of Disease Study 2015. Lancet 2016;388:1545-602.

2 Ostry AS, Spiegel JM. Labor markets and employment insecurity: impacts of globalization on service and healthcare-sector workforces. Int J Occup Environ Health 2004;10:368-74.

3 Gaynor M, Laudicella M, Propper C. Can governments do it better? Merger mania and hospital outcomes in the English NHS. J Health Econ 2012;31:528-43.

4 de Jong T, Wiezer N, de Weerd M, et al. The impact of restructuring on employee wellbeing: a systematic review of longitudinal studies. Work Stress 2016;30:91-114.

5 Jensen JH, Flachs EM, Skakon J, et al. Dual impact of organisational change on subsequent exit from work unit and sickness absence: a longitudinal study among public healthcare employees. Occup Environ Med 2018;75:479-85.

6 Westerlund H, Ferrie J, Hagberg J, et al. Workplace expansion, long-term sickness absence, and hospital admission. Lancet 2004;363:1193-7.

7 Kivimäki M, Vahtera J, Pentti J, et al. Downsizing, changes in work, and self-rated health of employees: A 7-year 3-wave panel study. Anxiety, Stress \& Coping 2001:14:59-73.

8 Bordia P, Hobman E, Jones E, et al. Uncertainty during organizational change: Types, consequences, and management strategies. J Bus Psychol 2004;18:507-32.

9 Bonde JP. Psychosocial factors at work and risk of depression: a systematic review of the epidemiological evidence. Occup Environ Med 2008;65:438-45.

10 Jensen HK, Wieclaw J, Munch-Hansen T, et al. Does dissatisfaction with psychosocial work climate predict depressive, anxiety and substance abuse disorders? A prospective study of Danish public service employees. J Epidemiol Community Health 2010;64:796-801.
11 Wieclaw J, Agerbo E, Mortensen PB, et al. Psychosocial working conditions and the risk of depression and anxiety disorders in the Danish workforce. BMC Public Health 2008;8:1-9.

12 Van Laethem M, Beckers DG, Kompier MA, et al. Psychosocial work characteristics and sleep quality: a systematic review of longitudinal and intervention research. Scand J Work Environ Health 2013:39:535-49.

13 Bamberger SG, Vinding AL, Larsen A, et al. Impact of organisational change on mental health: a systematic review. Occup Environ Med 2012;69:592-8.

14 Loretto W, Platt S, Popham F. Workplace change and employee mental health: results from a longitudinal study. Br J Manag 2010;21:526-40.

15 Greubel J, Kecklund G. The impact of organizational changes on work stress, sleep, recovery and health. Ind Health 2011;49:353-64.

16 Ferrie JE, Shipley MJ, Marmot MG, et al. The health effects of major organisational change and job insecurity. Soc Sci Med 1998;46:243-54.

17 Falkenberg $\mathrm{H}$, Fransson El, Westerlund $\mathrm{H}$, et al. Short- and long-term effects of major organisational change on minor psychiatric disorder and self-rated health: results from the Whitehall II study. Occup Environ Med 2013;70:688-96.

18 Netterstrøm B, Blønd M, Nielsen M, et al. Development of depressive symptoms and depression during organizational change--a two-year follow-up study of civil servants. Scand J Work Environ Health 2010;36:445-8.

19 Väänänen A, Ahola K, Koskinen A, et al. Organisational merger and psychiatric morbidity: a prospective study in a changing work organisation. J Epidemiol Community Health 2011;65:682-7.

20 Podsakoff PM, MacKenzie SB, Lee JY, et al. Common method biases in behavioral research: a critical review of the literature and recommended remedies. J App/ Psychol 2003;88:879-903.

21 Oreg S, Vakola M, Armenakis A. Change recipients' reactions to organizational change: A 60-year review of quantitative studies. J App/ Behav Sci 2011;47:461-524.

22 Kivimäki M, Honkonen T, Wahlbeck K, et al. Organisational downsizing and increased use of psychotropic drugs among employees who remain in employment. J Epidemiol Community Health 2007:61:154-8.

23 Blomqvist S, Alexanderson K, Vahtera J, et al. Downsizing and purchases of psychotropic drugs: A longitudinal study of stayers, changers and unemployed. PLOS One 2018;13:e0203433.

24 Magnusson Hanson LL, Westerlund H, Chungkham HS, et al. Purchases of prescription antidepressants in the swedish population in relation to major workplace downsizing. Epidemiology 2016;27:257-64.

25 Dahl MS. Organizational Change and Employee Stress. Manage Sci 2011;57:240-56.

26 Stansfeld S, Candy B. Psychosocial work environment and mental health--a metaanalytic review. Scand J Work Environ Health 2006;32:443-62.

27 Rosenquist JN, Fowler JH, Christakis NA. Social network determinants of depression. Mol Psychiatry 2011;16:273-81.

28 Bliese PD, Hanges PJ. Being both too liberal and too conservative: The perils of treating grouped data as though they were independent. Organ Res Methods 2004;7:400-17.

29 Vandenbroucke JP, von Elm E, Altman DG, et al. Strengthening the Reporting of Observational Studies in Epidemiology (STROBE): explanation and elaboration. Epidemiology 2007;18:805-35.

30 Hvidtfeldt UA, Bjorner JB, Jensen JH, et al. Cohort Profile: The Well-being in HospitAL Employees (WHALE) study. Int J Epidemiol 2017;46:1758-9.

31 Jensen JH, Flachs EM, Skakon J, et al. Longitudinal associations between organizational change, work-unit social capital, and employee exit from the work unit among public healthcare workers: a mediation analysis. Scand I Work Environ Health 201810.

32 George B. SS and IA. Survival analysis and regression models. NIH Public Access 2014:21:686-94.

33 Canette I. In the spotlight: Intraclass correlations after multilevel survival models. Stata News 2016;31 https://www.stata.com/stata-news/news31-2/intraclasscorrelations/.

34 de Mutsert R, Jager KJ, Zoccali C, et al. The effect of joint exposures: examining the presence of interaction. Kidney Int 2009;75:677-81.

35 Andersson T, Alfredsson L, Källberg $\mathrm{H}$, et al. Calculating measures of biological interaction. Eur J Epidemiol 2005;20:575-9.

36 Kent DM. Index Event Bias as an Explanation for the Paradoxes of Recurrence Risk Research. 2013;02111:25-6.

37 Koopmans PC, Bültmann U, Roelen CA, et al. Recurrence of sickness absence due to common mental disorders. Int Arch Occup Environ Health 2011;84:193-201.

38 Bordia P, Hunt E, Paulsen N, et al. Uncertainty during organizational change: Is it all about control? European Journal of Work and Organizational Psychology 2004; 13:345-65

39 Kivimäki M, Vahtera J, Pentti J, et al. Factors underlying the effect of organisational downsizing on health of employees: longitudinal cohort study. BMJ 2000;320:971-5. 